\title{
Tilting stability analysis and experiment of the 3-DOF lifting platform for hilly orchards
}

\author{
Zhenhua Duan ${ }^{1,2}$, Wei Qiu ${ }^{1,2}$, Weimin Ding ${ }^{1,2 *}$, Yande Liu' ${ }^{2}$, Yuping Ouyang ${ }^{2}$, Liang Huang ${ }^{1}$ \\ (1. College of Engineering, Nanjing Agricultural University, Nanjing 210031, China; 2. Co-Innovation Center of the Intelligent \\ Management and Equipment for Orchard on the Hilly Land in South China, Nanchang, 330013, China)
}

\begin{abstract}
An orchard-lifting platform is a type of mechanical equipment to assist growers in fruit picking, fruit tree pruning, flower thinning, and other operations. In its operational processes, the tilting stability directly affects the operational safety and adaptability under complex terrain conditions, while critical tilting angle is an important criterion to evaluate the tilting stability. Based on the structure and the operating characteristics of the three degree of freedom (3-DOF) lifting platform for hilly orchards, the tilting stability was analyzed in different parked states, and the theoretical expressions of critical tilting angle were obtained; in the theoretical expressions, the influencing factors on tilting stability were determined as the parked position $\beta_{1}$, the manned worktable rotary position $\beta_{2}$, the lifting height $h$, and the load $m$. Based on the multi-body dynamics principle, the tilting stability simulation was carried out. The relative error of tilting angles was approximately $4.6 \%$ between simulation and tilting verification experiment, which indicated that the results of tilting stability simulation were reliable. Therefore, the multi-body dynamics simulation was used for further clarifying the influencing factors on tilting stability. A virtual orthogonal test was designed, and the results showed that critical tilting angle ranged from $20^{\circ}$ to $44^{\circ}$ when the factors were at different values, which indicated that the 3-DOF lifting platform for hilly orchards had a high tilting stability performance and could adapt to the operating conditions of hills with slope angles from $5^{\circ}$ to $20^{\circ}$. The results of the range analysis and ANOVA showed that the influence intensity of factors on tilting stability was $\beta_{1}>h>m>\beta_{2}$; at the same time, $\beta_{1}, h$, and $m$ exerted significant effect on tilting stability. The tilting stability first decreased and then either increased or decreased with the increasing lifting height; it gradually decreased with the increasing load. It also showed that the position of the manned worktable along the slope down always had the lowest tilting stability. This research can provide a theoretical basis and reference for the analysis of tilting stability of the lifting machinery for hilly orchards.
\end{abstract}

Keywords: orchard-lifting platform, hills areas, tiling stability, influencing factors, analysis and experiment DOI: $10.25165 /$ j.ijabe.20181106.3523

Citation: Duan Z H, Qiu W, Ding W M, Liu Y D, Ouyang Y P, et al. Tilting stability analysis and experiment of the 3-DOF lifting platform for hilly orchards. Int J Agric \& Biol Eng, 2018; 11(6): 73-80.

\section{Introduction}

With the development of orchard mechanization, an increasing number of mechanical equipments have been developed for fruit picking, fruit tree pruning, flower thinning, and other operations, among which the more common is the orchard-lifting platform ${ }^{[1]}$. When the lifting platform is operating in fruit trees, the position of the center of gravity is changing with different operating actions. Due to the need to move in rows and the frequent start-stop modus, it is not suitable for the installation of auxiliary legs, which requires a higher tilting stability from the machine. Orchards in southern China are more concentrated in hilly areas, where the ground is undulating, and has more slopes with angles that range from $5^{\circ}$ to $20^{\circ}$. Operating in these terrains, a lower tilting stability is more

Received date: 2017-05-26 Accepted date: 2018-04-09

Biographies: Zhenhua Duan, $\mathrm{PhD}$ candidate, research interest: agricultural machinery design, Email: duanzhenhua1106@163.com; Wei Qiu, PhD, Lecturer, research interest: pesticide application technology, Email: qiuwei@njau.edu.cn; Yande Liu, PhD, Professor, research interest: light electromechanical integration technology and equipment, Email: jxliuyd@163.com; Yuping Ouyang, PhD, Lecturer, research interest: transport mechanization for hilly orchards, Email: ouyuping1987@163.com; Liang Huang, Master candidate, research interest: vehicle engineering, Email: 1538998005@qq.com.

*Corresponding author: Weimin Ding, PhD, Professor, research interest: agricultural machinery. No. 40, Dian Jiang Tai Road, Pukou District, Nanjing 210031, China. Tel: +86-25-58606502, Email: wmding@njau.edu.cn. likely to cause instability of the entire machine, even causing severe casualties and property damage. Therefore, the tilting stability is one of the most important performance indicators of the hilly orchard-lifting platforms.

More studies have been conducted on tilting stability of cars ${ }^{[2-7]}$ and heavy vehicles ${ }^{[8-11]}$ both at home and abroad, and the field of agriculture also mainly concentrates on tractors, harvesters, and other equipment. Zhao et al. ${ }^{[12]}$ proposed a dynamic solution to increase the tilting stability of an articulated tractor, explained the correctness of the solution through the model test, and proved the existence of second order instability. Gravalos et al. ${ }^{[13,14]}$ analyzed the influencing factors of the lateral stability of a tractor. Zhu et al. ${ }^{[15]}$ completed a general layout of the system design to improve side rollover resistant capability of the tracked vehicle for mountain orchards. Bruno et al. ${ }^{[16]}$ proposed an alternative model of impact that is better able to describe the rollover situation of a tractor. Liu et al. ${ }^{[17]}$ analyzed the influence of driving and structural parameters on the tilting stability via a virtual experiment of a corn harvester. Du et al. ${ }^{[18]}$ used ADAMS to construct a virtual prototype model of a small corn harvester on hilly land, and tested the critical tilting angle of the machine to avoid the actual vehicle test under dangerous conditions. Ma et al. ${ }^{[19]}$ constructed an accurate quasi-static lateral stability mathematical model of a corn harvester, and conducted a test and simulation analysis to verify the validity of their model. Maurizio et al. ${ }^{[20]}$ studied the lateral stability of self-propelled fruit harvesters and the main 
influencing factors were the position and mass of the operators and the fruit bin on the platform. Compared to the above equipment, the orchard-lifting platform has more operating activities, which results in the requirement of more complex tilting stability studies. In addition, the scissor structure is mainly used in current machinery ${ }^{[21-24]}$, but due to the limitation of the size of the worktable, the parked positions have to be constantly adjusted to improve the operating range. Moreover, these machines are more suitable for plain areas, and few of them work in hilly areas; furthermore, few studies investigate the tilting stability of lifting platforms.

According to the application status of the current orchard-lifting platforms in hilly areas, combined with the terrain conditions and the geometrical parameters of fruit trees to meet the complex operating environment of the hilly orchard, we developed a 3-DOF lifting platform, which can assist the fruit farmers to complete the orchard picking and pruning operations when it is in the parked state. Based on an analysis of its structural composition and operating characteristics, this study mainly analyzed the tilting stability of the whole machine, and obtained the influencing factors of stability. Then, the influence of various factors was studied on the tilting stability through both virtual simulation and experimental verification. According to the results of the study, this can explain whether the platform can adapt to the slope operating conditions of hilly orchards or not.

\section{Materials and methods}

\subsection{Whole structural and working principle of the lifting} platform

The lifting mechanism of the 3-DOF lifting platform was developed as a folding-arm system, which can manually lift and rotate to support fruit picking, fruit tree pruning, and other processes. Additionally, the manned worktable can be leveled via a leveling device when the ground is uneven. The proposed 3-DOF lifting platform consists of a manned worktable, a lifting device, a power device, a walking device, and a leveling device. As shown in Figure 1, the lifting device is mainly composed of a folding-arm, slewing bearing, lifting hydraulic cylinder, hydraulic pump station, and an electromagnetic valve group. The leveling device consists of a leveling cylinder and a leveling turbo-worm. The walking device adopts an agricultural crawler chassis.

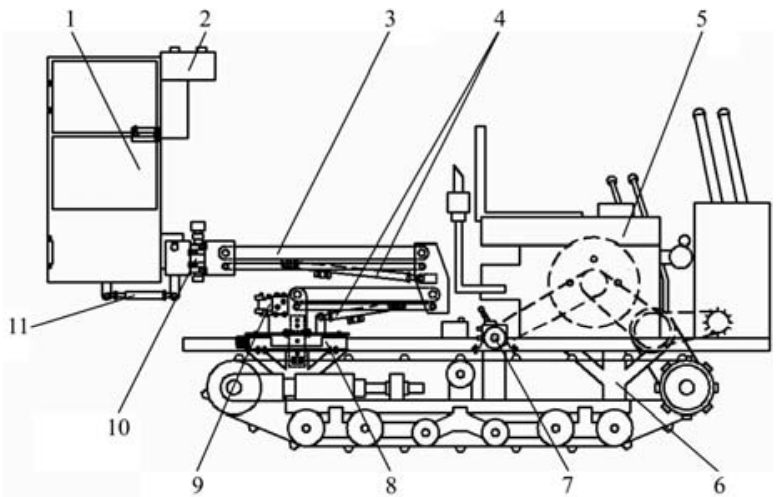

1. Manned worktable 2. Control box 3. Folding-arm 4. Lifting hydraulic cylinder 5. Diesel engine 6. Agricultural crawler chassis 7. Hydraulic pump station 8. Slewing bearing 9. Solenoid valve group 10. Leveling turbo-worm 11. Leveling cylinder

Figure 1 Whole structural diagram of the 3-DOF lifting platform for hilly orchards

The farmers standing on the manned worktable can reach the appropriate operating position by controlling the lifting device to lift and rotate, and can level the worktable in all four directions (front, back, left, and right) by controlling the leveling cylinder and the leveling turbo-worm. The main technical parameters of the platform are summarized in Table 1.

Table 1 Main parameters of lifting platform for hilly orchards

\begin{tabular}{lc}
\multicolumn{1}{c}{ Parameters } & Values \\
\hline Dimensions $(\mathrm{L} \times \mathrm{W} \times \mathrm{H}) / \mathrm{mm}$ & $2730 \times 1500 \times 1900$ \\
Dimensions of manned worktable $(\mathrm{L} \times \mathrm{W} \times \mathrm{H}) / \mathrm{mm}$ & $500 \times 1000 \times 1000$ \\
Power $/ \mathrm{kW}$ & 16.2 \\
Weight $/ \mathrm{kg}$ & 1531.5 \\
Maximum load $/ \mathrm{kg}$ & 150 \\
Maximum lifting height $/ \mathrm{m}$ & 1.2 \\
Maximum operating radius $/ \mathrm{m}$ & 1.4 \\
Angle of leveling $/\left(^{\circ}\right)$ & \pm 25 \\
\hline
\end{tabular}

\subsection{Tilting stability analysis of the 3-DOF lifting platform}

Tilting stability is an important indicator for normal operation of the lifting platform for orchards on hilly areas, and the critical angle is often used to characterize the level of tilting stability. Furthermore, the larger the critical tilting angle, the higher the tilting stability will be. Additionally, the platform can park at any position on the slope, and has a longitudinal critical tilting angle along the longitudinal direction of the slope, has a transverse critical tilting angle along the transverse direction of the slope, and has a critical tilting angle along the oblique direction determined by the angles in longitudinal direction and transverse direction.

(1) Critical tilting angle in the longitudinal direction

All variables are defined: $O^{\prime}$ is the geometric of the chassis table; $O$ is the projection of $O^{\prime}$ on the slope; $O^{\prime \prime}$ is the mounting point of the lifting part on the chassis table; $a$ is the distance between $O^{\prime \prime}$ and $O^{\prime}$ in vertical direction $(\mathrm{m}) ; b$ is the distance between $O^{\prime \prime}$ and $O^{\prime}$ in horizontal direction (m); $h_{1}$ is the height of the chassis table $(\mathrm{m}) ; h_{2}$ is the load height from the chassis table without lifting $(\mathrm{m}) ; h$ is the lifting height $(\mathrm{m}) ; r$ is the operating radius $(\mathrm{m}) ; \alpha$ is the slope angle $\left(^{\circ}\right) ; \beta_{1}$ is the angle between the front of the lifting platform and the uphill direction $\left(^{\circ}\right)$, and counterclockwise is the positive direction; $\beta_{2}$ is the rotating angle $\left({ }^{\circ}\right)$, and counterclockwise is the positive direction; $M$ is the weight of the platform $(\mathrm{kg}) ; m$ is the load on the worktable $(\mathrm{kg}) ; P_{N}$ is the rejecting force $(\mathrm{N}) ; P_{f}$ is the static friction force $(\mathrm{N}) ; L$ is the track grounded length (m); $l$ is the distance from $P_{N}$ to the tilting edge of the track (m); $O_{1}$ is the supporting point of the rear edge of the bearing surface, and $\mathrm{O}_{2}$ is the supporting point of the front edge of the bearing surface.

As shown in Figure 2, $O$ is set as the origin, the front side of the lifting platform is the $x$-axis positive direction, the left side is the $y$-axis positive direction, and the vertical crawler chassis table is the positive $z$-axis positive direction. Then, the coordinate system $O_{x y z}$ is established. When the manned workbench is unload, the center of gravity coordinates are $\left(e_{x}, e_{y}, e_{z}\right)$.

The platform parking along the uphill slope in longitudinal direction is shown in Figure $2 \mathrm{a}$, and $\beta_{1}$ is $0^{\circ}$ at this time. When tilting happens from $O_{1}$, the moment balance equation $\sum M_{O_{1}}=0$ can be expressed as:

$$
\begin{aligned}
& m g \sin \alpha\left(h_{1}+h_{2}+h\right)-m g \cos \alpha\left(0.5 L+a-\cos \beta_{2} r\right)+ \\
& M g \sin \alpha e_{z}-M g \cos \alpha\left(0.5 L+e_{x}\right)+P_{N} l=0
\end{aligned}
$$

Equation (1) shows that with the increase of slope angle $\alpha, l$ gradually decreases, and the rejection force $P_{N}$ gradually moves to the rear edge of the bearing surface. When $l$ is $0 \mathrm{~m}, P_{N}$ is all at $O_{1}$, 
and the platform will be tilted. Therefore, when $\beta_{1}$ is $0^{\circ}$, the condition for no tilting in the longitudinal direction is: $l \geq 0$, and the critical tilting angle is:

$$
\alpha \leq \arctan \frac{M\left(0.5 L+e_{x}\right)+m\left(0.5 L+a-\cos \beta_{2} r\right)}{M e_{z}+m\left(h_{1}+h_{2}+h\right)}
$$

When $\beta_{2}$ is $0^{\circ}$ or $360^{\circ}$, there is a minimum critical tilting angle, at this time $\beta_{2}$ is equal to $-\beta_{1}$ or $-\beta_{1}+360^{\circ}$.

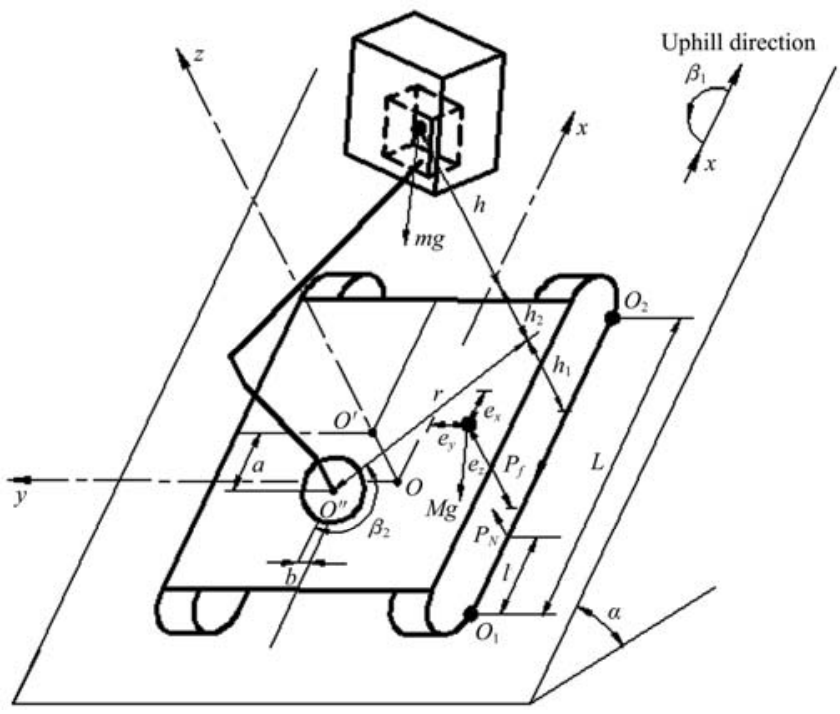

a. Platform is parked along the uphill direction

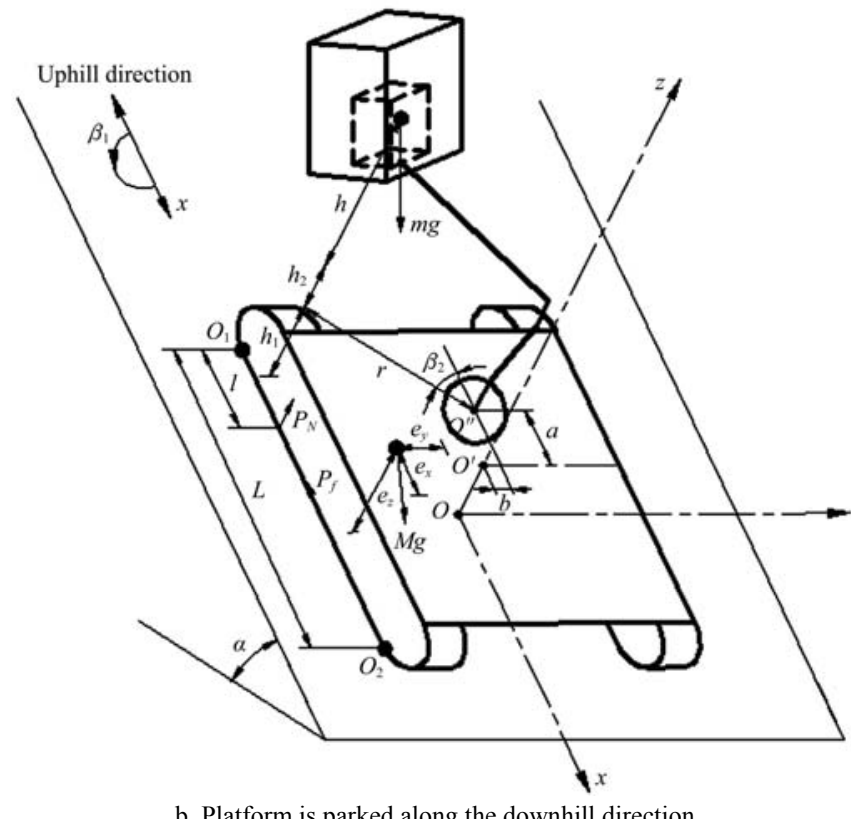

Figure 2 Schematic diagram of longitudinal tilting stability

Similarly, as shown in Figure $2 \mathrm{~b}, \beta_{1}$ is $180^{\circ}$; when the platform happens to tilt from $\mathrm{O}_{2}$, then, the moment balance equation $\sum M_{\mathrm{O}_{2}}=0$ can be expressed as:

$$
\begin{aligned}
& m g \cos \alpha\left(0.5 L-a+\cos \beta_{2} r\right)-m g \sin \alpha\left(h_{1}+h_{2}+h\right)+ \\
& M g \cos \alpha\left(0.5 L-e_{x}\right)-M g \sin \alpha e_{z}-P_{N}(L-l)=0
\end{aligned}
$$

Then, the condition for no tilting in the longitudinal direction when $\beta_{1}$ is $180^{\circ}$ is: $L-l \geq 0$, and the critical tilting angle is:

$$
\alpha \leq \arctan \frac{M\left(0.5 L-e_{x}\right)+m\left(0.5 L-a+\cos \beta_{2} r\right)}{M e_{z}+m\left(h_{1}+h_{2}+h\right)}
$$

Equations (2) and (4) show that the longitudinal tilting stability of the lifting platform along the slope is related to $\beta_{1}, \beta_{2}, h, r, m, e_{x}$, and $e_{z}$. Furthermore, when $\beta_{2}$ is equal to $-\beta_{1}$ or $-\beta_{1}+360^{\circ}$, a minimum critical tilting angle always exists.

(2) Critical tilting angle in the transverse direction

All variables are defined: $B$ is the gauge of the crawler $(\mathrm{m}) ; c$ is the width of the crawler $(\mathrm{m}) ; P_{N 1}$ is the rejecting force on the left track $(\mathrm{N}) ; P_{N 2}$ is the rejecting force on the right track $(\mathrm{N}) ; P_{f 1}$ is the static friction force on the left track $(\mathrm{N}) ; P_{f 2}$ is the static friction force on the right track $(\mathrm{N}) ; O_{3}$ is the center point of the left track; $\mathrm{O}_{4}$ is the center point of the right track; $\mathrm{O}_{5}$ is the tilting edge point of the left track, and $O_{6}$ is the tilting edge point of the right track.

As shown in Figure 3, at this time $\beta_{1}$ is $90^{\circ}$; when the platform happens to tilt from $O_{5}$, the moment balance equation $\sum M_{O_{5}}=0$ can be expressed as:

$$
\begin{aligned}
& M g \sin \alpha e_{z}-M g \cos \alpha\left(\frac{B+c}{2}-e_{y}\right)+P_{N_{2}}\left(B+\frac{c}{2}\right)+ \\
& m g \sin \alpha\left(h_{1}+h_{2}+h\right)-m g \cos \alpha\left(\frac{B+c}{2}-b+\sin \beta_{2} r\right)=0
\end{aligned}
$$

Equation (5) shows that with the increase of $\alpha$, the rejecting force $P_{N 2}$ on the right track gradually decreases, and moves from $O_{4}$ to $O_{6}$, while the rejecting force $P_{N 1}$ on the left track moves from $O_{3}$ to $O_{5}$. When $P_{N 2}$ is decreased to 0 , and $P_{N 1}$ is forced on $O_{5}$, the platform will be tilted in the transverse direction. Therefore, when $\beta_{1}$ is $90^{\circ}$, the condition for no tilting in the transverse direction is: $P_{N 2} \geq 0$, and the critical tilting angle is:

$$
\alpha \leq \arctan \frac{M\left(0.5 B+0.5 c-e_{y}\right)+m\left(0.5 B+0.5 c-b+\sin \beta_{2} r\right)}{M e_{z}+m\left(h_{1}+h_{2}+h\right)}(6)
$$

Similarly, when $\beta_{1}$ is $270^{\circ}$, the condition for no tilting in the transverse direction is: $P_{N 1} \geq 0$, and the critical tilting angle is:

$$
\alpha \leq \arctan \frac{M\left(0.5 B+0.5 c+e_{y}\right)+m\left(0.5 B+0.5 c+b-\sin \beta_{2} r\right)}{M e_{z}+m\left(h_{1}+h_{2}+h\right)}
$$

Equations (5) and (7) show that the transverse tilting stability of the lifting platform along the slope is related to $\beta_{1}, \beta_{2}, h, r, m, e_{y}$, and $e_{z}$. Furthermore, when $\beta_{2}$ is equal to $-\beta_{1}$ or $-\beta_{1}+360^{\circ}$, a minimum critical tilting angle always exists too.

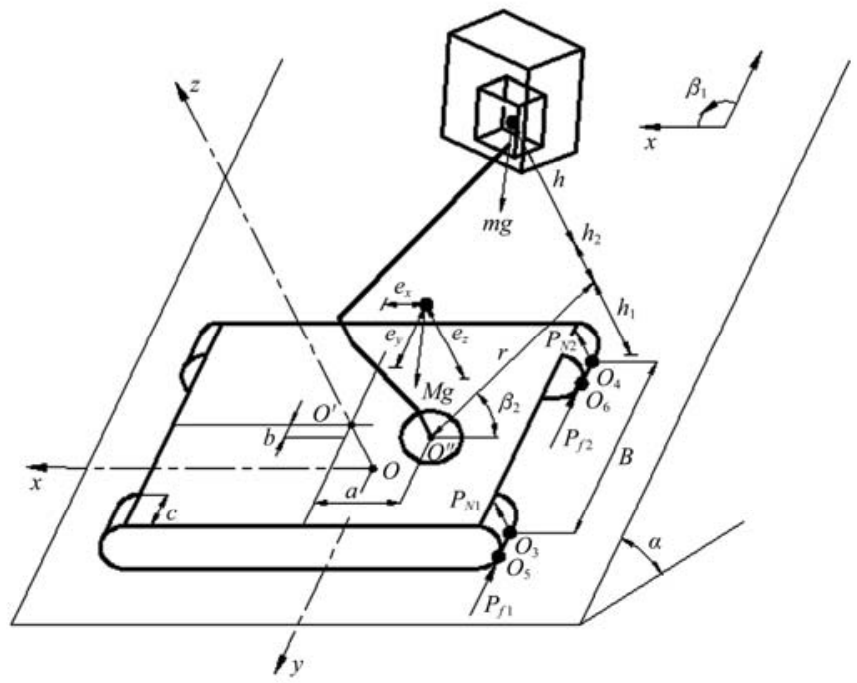

Figure 3 Schematic diagram of transverse tilting stability

(3) Critical tilting angle in the oblique direction

When the lifting platform is parked on the slope in the oblique direction, the components of $M g$ and $m g$ in the longitudinal direction are $M g \sin \alpha \cos \beta_{1}$ and $m g \sin \alpha \cos \beta_{1}$, respectively. The components in the transverse direction are $M g \sin \alpha \sin \beta_{1}$ and $m g \sin \alpha \sin \beta_{1}$, respectively. The critical tilting angles in the longitudinal and transverse direction are set as $\alpha^{\prime}, \alpha^{\prime \prime}$, which can be expressed as: 


$$
\begin{aligned}
& \alpha^{\prime} \leq \arctan \frac{M\left(0.5 L+e_{x}\right)+m\left(0.5 L+a-\cos \beta_{2} r\right)}{\left[M e_{z}+m\left(h_{1}+h_{2}+h\right)\right] \cos \beta_{1}} \text { or } \\
& \alpha^{\prime} \leq \arctan \frac{M\left(0.5 L-e_{x}\right)+m\left(0.5 L-a+\cos \beta_{2} r\right)}{\left[M e_{z}+m\left(h_{1}+h_{2}+h\right)\right] \cos \beta_{1}}, \\
& \alpha^{\prime \prime} \leq \arctan \frac{M\left(0.5 B+0.5 c-e_{y}\right)+m\left(0.5 B+0.5 c-b+\sin \beta_{2} r\right)}{\left[M e_{z}+m\left(h_{1}+h_{2}+h\right)\right] \sin \beta_{1}}
\end{aligned}
$$

or

$$
\alpha^{\prime \prime} \leq \arctan \frac{M\left(0.5 B+0.5 c+e_{y}\right)+m\left(0.5 B+0.5 c+b-\sin \beta_{2} r\right)}{\left[M e_{z}+m\left(h_{1}+h_{2}+h\right)\right] \sin \beta_{1}}
$$

Then, the critical tilting angle in the oblique direction is:

$$
\left\{\begin{array}{l}
\alpha^{\prime}, \alpha^{\prime} \leq \alpha^{\prime \prime} \\
\alpha^{\prime \prime}, \alpha^{\prime}>\alpha^{\prime \prime}
\end{array}\right.
$$

(4) Influencing factors

The tilting stability analysis of the 3-DOF lifting platform in three operating states indicates that the tilting stability is related to the operating parameters $\beta_{1}, \beta_{2}, h, r, m$, and the center of gravity coordinates $e_{x}, e_{y}$, and $e_{z}$. Moreover, $r$ changes with the change of $h$, similarly, $e_{x}, e_{y}$, and $e_{z}$ change with the change of $\beta_{2}, h$, and $m$. In summary, the influencing factors of the tilting stability are $\beta_{1}, \beta_{2}$, $h$, and $m$, and when $\beta_{2}$ is equal to $-\beta_{1}$ or $-\beta_{1}+360^{\circ}$, there is always a minimum critical tilting angle, i.e., the position of the manned worktable along the slope down is always the most prone to tilt, and the platform has the lowest tilting stability.

\subsection{Virtual simulation and experiment verification}

\subsubsection{Establishment of a virtual prototype model}

Based on the whole structure and parameters of each component, a virtual prototype model was established in UG 8.0. To reduce the number of model constraints and to shorten simulation time, the non-operating components were merged through a Boolean operation under the conditions that the components needed in simulation are consistent with the real situation. The virtual prototype model of the 3-DOF lifting platform for hilly orchards is shown in Figure 4. Its total mass was $1530.9 \mathrm{~kg}$ (obtained through the measurement tool), which is basically the same as the platform. The model is converted to Parasolid format to reduce information loss, and to obtain higher fidelity ${ }^{[25]}$. Then, the model was imported to the simulation software for tilting stability simulation.

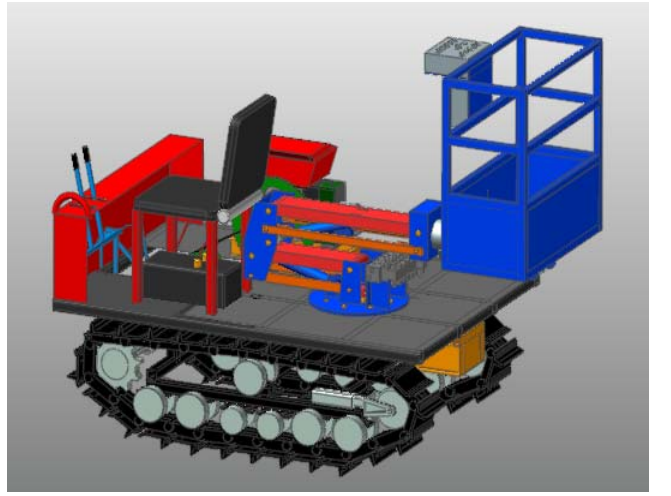

Figure 4 Virtual prototype model for the lifting platform

\subsubsection{Virtual simulation}

Multi-body system dynamics simulation software RecurDyn ${ }^{[26]}$ was used for the virtual simulation. The prototype model was imported and a tilting table was built, constraints were set and driven to simulate the tilting process. Assuming that the frictional force between the tilting table and the track was sufficient, no slip occurred; then, the static friction coefficient was set to be 3.0 according to other simulation studies ${ }^{[27]}$ and experience value (2.8-3.0), which had been proved effective through a preliminary simulation. At last, the effect type of the track with the table was set to Contact ${ }^{[28]}$. However, to ensure safety of the operation, the platform should be shut down before tilting in practice, so a contact block marked $P$ was set on the middle of the left or right track grousers in the simulation. The critical tilting angle was determined by a change of the rejecting force $P_{N}$ at $P$; when $P_{N}$ is $0 \mathrm{~N}$, the simulation value of the critical tilting angle was the slope angle at this time, which could be recorded as $\alpha_{0}\left(^{\circ}\right)$.

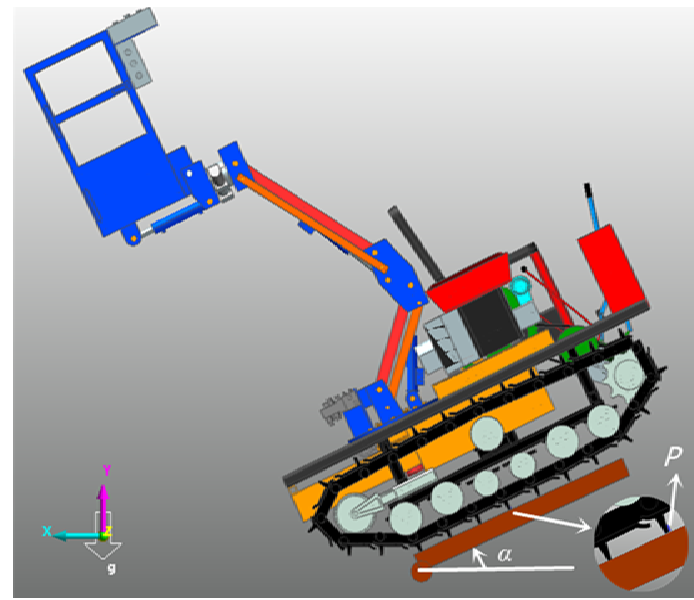

a. Tilting simulation process in the longitudinal direction

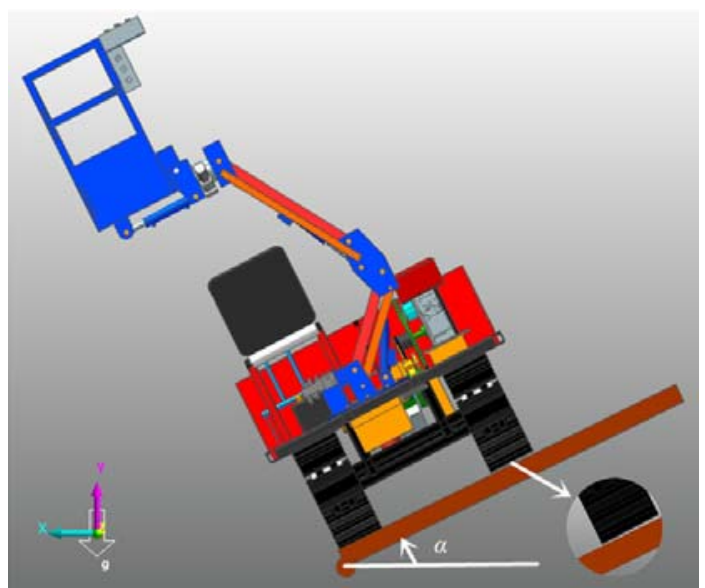

b. Tilting simulation process in the transverse direction

Figure 5 Schematic diagram of the tilting simulation processes

Figures $5 \mathrm{a}$ and $5 \mathrm{~b}$ show the tilting simulation processes of the lifting platform with a load of $150 \mathrm{~kg}$ and a lifting height of $1.2 \mathrm{~m}$ in the longitudinal direction $\left(\beta_{1}\right.$ is $\left.0^{\circ}\right)$ and transverse direction $\left(\beta_{1}\right.$ is $90^{\circ}$ ), respectively.

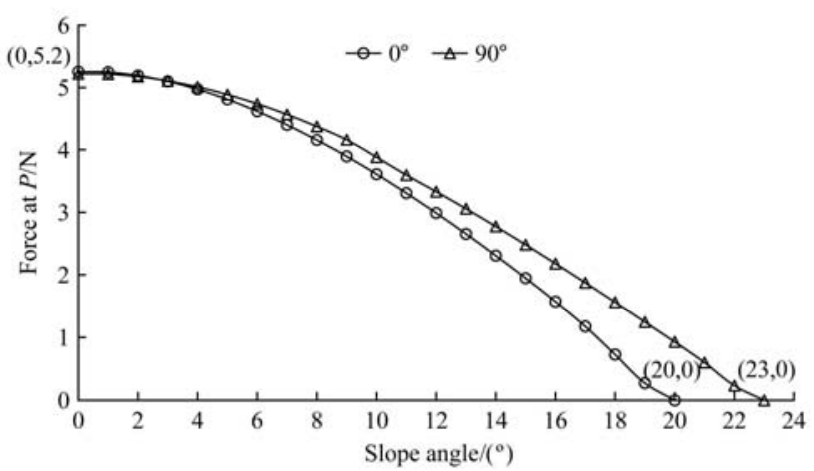

Figure 6 Curve of the supporting force as slope angle increased

The simulation results are shown in Figure 6, and the maximum of $P_{N}$ was about $5.2 \mathrm{~N}$, which was small enough that the 
block $P$ has little impact on the simulation results. When the slope angle $\alpha$ increased to $20^{\circ}, P_{N}$ decreased to $0 \mathrm{~N}$, and the simulation value of the critical tilting angle $\alpha_{0}$ was $20^{\circ}\left(\beta_{1}\right.$ was $\left.0^{\circ}\right)$. Similarly, When the slope angle $\alpha$ increased to $23^{\circ}, P_{N}$ decreased to $0 \mathrm{~N}$, and the simulation value of the critical tilting angle $\alpha_{0}$ was $23^{\circ}$ $\left(\beta_{1}\right.$ was $\left.90^{\circ}\right)$.

Furthermore, with reference to the above simulation processes, the critical tilting angle of the orchard-lifting platform could be obtained with different values of the influencing factors. According to the technical parameters of the platform, the influencing factors $\beta_{1}, \beta_{2}, h$, and $m$ were set as follows:

(1) Parked position: as the platform can be parked at any position on the slope, with $45^{\circ}$ for interval, $\beta_{1}$ was set to $0^{\circ}, 45^{\circ}$, $90^{\circ}, 135^{\circ}, 180^{\circ}, 225^{\circ}, 270^{\circ}$ and $315^{\circ}$.

(2) Rotary position: since the position manned worktable along the slope down was always the most prone to tilt in the same operating conditions, it was most able to reflect the tilting stability and $\beta_{2}$ was therefore set to $-\beta_{1}$.

(3) Lifting height: according to the maximum lifting height of $1.2 \mathrm{~m}$ and combined with the longitudinal crown of fruit trees, with $0.4 \mathrm{~m}$ for interval, $h$ was set to $0 \mathrm{~m}, 0.4 \mathrm{~m}, 0.8 \mathrm{~m}$ and $1.2 \mathrm{~m}$.

(4) Load: according to the maximum load of $150 \mathrm{~kg}$, with $50 \mathrm{~kg}$ for intervals, $m$ was set to $0 \mathrm{~kg}, 50 \mathrm{~kg}, 100 \mathrm{~kg}$ and $150 \mathrm{~kg}$.

The simulation results are listed in Table 2.

Table 2 Simulation results of the critical tilting angle

\begin{tabular}{|c|c|c|c|c|c|c|c|c|c|c|c|c|c|c|c|c|}
\hline \multirow{3}{*}{$\begin{array}{c}\text { Parked } \\
\left.\text { position/ } /{ }^{\circ}\right)\end{array}$} & \multicolumn{16}{|c|}{ Critical tilting angle at different lifting heights with different loads $/\left(^{\circ}\right)$} \\
\hline & \multicolumn{4}{|c|}{$0 \mathrm{~kg}$} & \multicolumn{4}{|c|}{$50 \mathrm{~kg}$} & \multicolumn{4}{|c|}{$100 \mathrm{~kg}$} & \multicolumn{4}{|c|}{$150 \mathrm{~kg}$} \\
\hline & $0 \mathrm{~m}$ & $0.4 \mathrm{~m}$ & $0.8 \mathrm{~m}$ & $1.2 \mathrm{~m}$ & $0 \mathrm{~m}$ & $0.4 \mathrm{~m}$ & $0.8 \mathrm{~m}$ & $1.2 \mathrm{~m}$ & $0 \mathrm{~m}$ & $0.4 \mathrm{~m}$ & $0.8 \mathrm{~m}$ & $1.2 \mathrm{~m}$ & $0 \mathrm{~m}$ & $0.4 \mathrm{~m}$ & $0.8 \mathrm{~m}$ & $1.2 \mathrm{~m}$ \\
\hline 0 & 31 & 30 & 28 & 28 & 28 & 26 & 23 & 24 & 25 & 23 & 21 & 22 & 23 & 21 & 20 & 20 \\
\hline 45 & 33 & 31 & 29 & 30 & 31 & 29 & 27 & 27 & 29 & 26 & 24 & 25 & 26 & 24 & 22 & 23 \\
\hline 90 & 32 & 30 & 29 & 29 & 29 & 27 & 26 & 27 & 28 & 25 & 24 & 25 & 26 & 23 & 22 & 23 \\
\hline 180 & $*$ & $*$ & 31 & 34 & $*$ & $*$ & 30 & 31 & $*$ & $*$ & 29 & 29 & $*$ & $*$ & 27 & 28 \\
\hline 225 & $*$ & 29 & 28 & 29 & $*$ & 27 & 26 & 26 & $*$ & 24 & 23 & 24 & $*$ & 23 & 22 & 22 \\
\hline 270 & $*$ & 30 & 28 & 28 & $*$ & 28 & 25 & 25 & $*$ & 25 & 24 & 24 & $*$ & 23 & 21 & 21 \\
\hline 315 & 33 & 31 & 30 & 31 & 31 & 29 & 28 & 28 & 29 & 28 & 25 & 26 & 27 & 24 & 22 & 24 \\
\hline
\end{tabular}

Note: * represents a position outside of the reach of the manned worktable (similarly hereinafter).

On the other hand, in order to save time and improve operating efficiency, the worktable may stop at an operating position (except for some limit operation positions including the maximum lifting height and the maximum operating radius), while the platform is moving. Moreover, it only happens in a short movement when the sloping road is relatively flat, such as moving from one tree to the next. Similarly, there is also a dynamic tilting angle, which can be recorded as $\alpha_{0}{ }^{\prime}$. Therefore, dynamic tilting simulation of climbing and lateral driving at a certain lifting height and load was carried out. Taking the actual operation into account, $h$ was set to $0.4 \mathrm{~m}$ and $0.8 \mathrm{~m}, m$ was set to $100 \mathrm{~kg}$, the manned worktable was always along the slope down, and the speed was set to $0.42 \mathrm{~m} / \mathrm{s}$.

Figure 7 shows the dynamic tilting simulation processes when the lifting platform was climbing with a lifting height of $0.8 \mathrm{~m}$ and a load of $100 \mathrm{~kg}$. When the slope angle is $10^{\circ}, 15^{\circ}$ and $19^{\circ}$, the displacement of manned worktable in Y direction increased slowly, which indicated that the lifting platform can climb normally on these slopes. However, the displacement happened to drop sharply from $2 \mathrm{~s}$ to $3.5 \mathrm{~s}$ when the slope angle was $20^{\circ}$, which showed that the lifting platform tilted. Therefore, the dynamic tilting angle of climbing process was considered to be $20^{\circ}$.

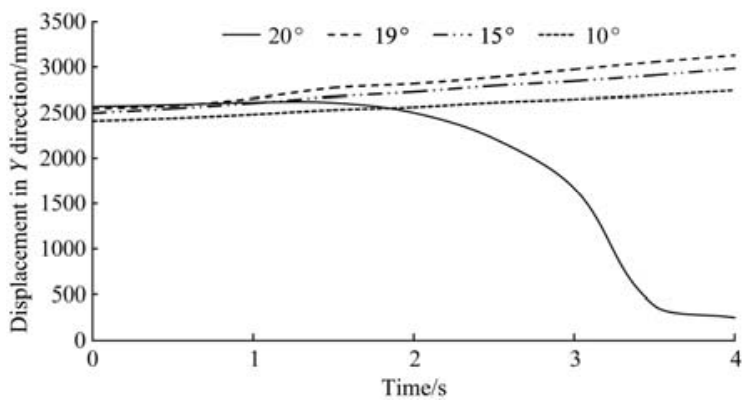

Figure 7 Displacement in $Y$ direction at different slope angles

Furthermore, by referring to the above simulation processes, the dynamic tilting angles of climbing in other conditions and lateral driving were obtained. As shown in Table 3, the dynamic tilting angles of climbing were $21^{\circ}$ and $20^{\circ}$; the dynamic tilting angles of left lateral driving were $24^{\circ}$ and $23^{\circ}$; the dynamic tilting angles of right lateral driving were $23^{\circ}$ and $22^{\circ}$. Compared with the static tilting angles, the dynamic tilting angles were only $1^{\circ}-2^{\circ}$ smaller.

Table 3 Simulation results of the dynamic tilting angle

\begin{tabular}{llllll}
\hline \multirow{2}{*}{ Process } & \multicolumn{3}{c}{$0.4 \mathrm{~m}$} & \multicolumn{2}{c}{$0.8 \mathrm{~m}$} \\
\cline { 2 - 6 } & $\alpha_{0}{ }^{\prime}$ & $\alpha_{0}$ & & $\alpha_{0}{ }^{\prime}$ & $\alpha_{0}$ \\
\hline Climbing & 21 & 23 & 20 & 21 \\
\hline Left lateral driving & 24 & 25 & 23 & 24 \\
Right lateral driving & 23 & 25 & & 22 & 24 \\
\hline
\end{tabular}

\subsubsection{Experimental verification}

To verify the validity of this virtual simulation, an experiment on the tilting stability of the 3-DOF lifting platform for hilly orchards was conducted in October, 2016 in the Institute of Engineering, Nanjing Agricultural University. The maximum angle of tilting test table is $30^{\circ}$, the length of table is $4 \mathrm{~m}$, the width is $5 \mathrm{~m}$, and the start-stop mode is the electric control. Test tools include tape measure, benchmark, digital angle meter, safety rope, and others. The experimental results are shown in Table 4, and tilting experiments in progress are shown in Figure 8.

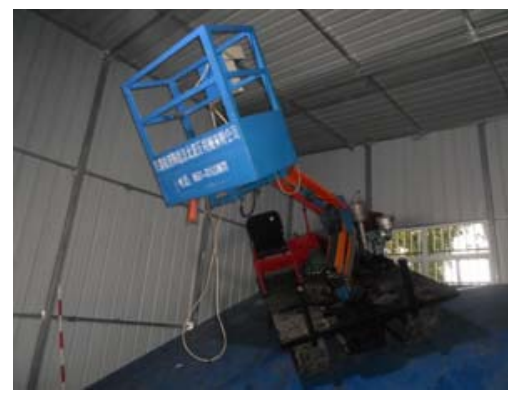

Figure 8 Tilting experiments in progress 
Table 4 Experiment for tilting stability

\begin{tabular}{|c|c|c|c|c|c|c|c|c|c|c|c|c|c|c|c|c|}
\hline \multirow{3}{*}{$\begin{array}{c}\text { Parked } \\
\text { position } /\left(^{\circ}\right)\end{array}$} & \multicolumn{16}{|c|}{ Critical tilting angle at different lifting heights with different loads $/\left(^{\circ}\right)$} \\
\hline & \multicolumn{4}{|c|}{$0 \mathrm{~kg}$} & \multicolumn{4}{|c|}{$50 \mathrm{~kg}$} & \multicolumn{4}{|c|}{$100 \mathrm{~kg}$} & \multicolumn{4}{|c|}{$150 \mathrm{~kg}$} \\
\hline & $0 \mathrm{~m}$ & $0.4 \mathrm{~m}$ & $0.8 \mathrm{~m}$ & $1.2 \mathrm{~m}$ & $0 \mathrm{~m}$ & $0.4 \mathrm{~m}$ & $0.8 \mathrm{~m}$ & $1.2 \mathrm{~m}$ & $0 \mathrm{~m}$ & $0.4 \mathrm{~m}$ & $0.8 \mathrm{~m}$ & $1.2 \mathrm{~m}$ & $0 \mathrm{~m}$ & $0.4 \mathrm{~m}$ & $0.8 \mathrm{~m}$ & $1.2 \mathrm{~m}$ \\
\hline 0 & $>30$ & $>30$ & 29.2 & $>30$ & 28.8 & 27.4 & 25.7 & 26.1 & 27.4 & 23.9 & 22.6 & 23.7 & 26.1 & 20.4 & 19.3 & 21.4 \\
\hline 45 & $>30$ & $>30$ & $>30$ & $>30$ & $>30$ & $>30$ & 27.8 & 28.1 & $>30$ & 26.3 & 24.1 & 25.2 & 26.7 & 23.1 & 22.8 & 23.3 \\
\hline 90 & $>30$ & $>30$ & $>30$ & $>30$ & 29.5 & 29.1 & 28.2 & 28.5 & 28.8 & 27.4 & 24.9 & 25.6 & 27.8 & 25.3 & 23.8 & 24.5 \\
\hline 135 & $*$ & $>30$ & $>30$ & $>30$ & $*$ & $>30$ & $>30$ & $>30$ & $*$ & $>30$ & $>30$ & $>30$ & $*$ & 28.8 & 27.2 & 28.1 \\
\hline 180 & $*$ & $*$ & $>30$ & $>30$ & $*$ & $*$ & $>30$ & $>30$ & $*$ & $*$ & $>30$ & $>30$ & $*$ & $*$ & 28.4 & 29.8 \\
\hline 225 & $*$ & $>30$ & $>30$ & $>30$ & $*$ & 27.8 & 26.3 & 26.8 & $*$ & 26.5 & 25.3 & 25.7 & $*$ & 25.2 & 23.9 & 24.6 \\
\hline 270 & $*$ & $>30$ & 29.4 & $>30$ & $*$ & 27.1 & 25.7 & 26.2 & $*$ & 24.9 & 24.1 & 24.3 & $*$ & 22.5 & 20.7 & 21.9 \\
\hline 315 & $>30$ & $>30$ & $>30$ & $>30$ & $>30$ & $>30$ & 29.2 & $>30$ & $>30$ & $>30$ & 25.4 & 26.1 & 27.6 & 24.3 & 21.2 & 22.1 \\
\hline
\end{tabular}

The effective value of the tilting angle ranged from $19.3^{\circ}$ to $30^{\circ}$, and others were beyond the range of the tilting test table. Values of simulation results were selected in the same position which had the effective values of experimental results in Table 4. The average relative error could be calculated according to equation as follows:

$$
e=\frac{\sum\left|\left(\alpha_{0}-\alpha_{1}\right) / \alpha_{1}\right|}{N} \times 100 \%
$$

where, $e$ is the average relative error, $\% ; \alpha_{0}$ is the simulation value of the critical tilting angle, $\left({ }^{\circ}\right) ; \alpha_{1}$ is the experiment value of the critical tilting angle, $\left({ }^{\circ}\right) ; N$ is the number of the groups of effective values (here, 64 groups).

The relative error between the simulation value and the experimental value was only $4.6 \%$, which indicated that the simulation of the tilting stability had a high accuracy, and the tilting angles could guide the actual operation and performance experiment. At the same time, it provided a method to conveniently predict the critical tilting angle at the start of machine design. Therefore, the virtual simulation could be used to further analyze the influencing factors on tilting stability.

2.3.4 Influencing factor analysis

The influencing factors were the parked position $\beta_{1}$, the rotary position $\beta_{2}$, the lifting height $h$, and the load $m$, and in order to clarify the influence of these on tilting stability, a virtual orthogonal test should be carried out. Based on the tilting simulation processes, the levels of the factors were properly selected and an orthogonal table $\mathrm{L}_{64}\left(8^{4}\right)$ was designed ${ }^{[29-30]}$. The factors and the levels of the orthogonal test are shown in Table 5.

Table 5 Factors and levels of the virtual orthogonal test

\begin{tabular}{ccccc}
\hline Level & $\beta_{1} /\left(^{\circ}\right)$ & $\beta_{2} /\left(^{\circ}\right)$ & $h / \mathrm{m}$ & $m / \mathrm{kg}$ \\
\hline 1 & 0 & 0 & 0.5 & 0 \\
2 & 45.0 & 45.0 & 0.6 & 21.4 \\
3 & 90.0 & 90.0 & 0.7 & 42.8 \\
4 & 135.0 & 135.0 & 0.8 & 62.4 \\
5 & 180.0 & 180.0 & 0.9 & 85.6 \\
6 & 225.0 & 225.0 & 1.0 & 107.0 \\
7 & 270.0 & 270.0 & 1.1 & 128.4 \\
8 & 315.0 & 315.0 & 1.2 & 150.0 \\
\hline
\end{tabular}

\section{Results and discussion}

The results of the virtual orthogonal test are shown in Table 6 , and $A, B, C$ and $D$ were the coding values of $\beta_{1}, \beta_{2}, h$ and $m$, respectively. The critical tilting angle $\left(\alpha_{0}\right)$ ranged from $20^{\circ}$ to $44^{\circ}$ when the factors were at different values, which indicated that the 3-DOF lifting platform for hilly orchards had a high tilting stability performance, met the design requirements and could adapt to the operating conditions of hills with slope angles from $5^{\circ}$ to $20^{\circ}$. Compared with current lifting platforms and other agricultural machinery, this lifting platform had a better tilting stability, such as the scissor orchard-lifting platform only having the tilting angle from $15^{\circ}$ to $30^{\circ[23]}$, in addition, the maximum lateral tilting angle without load of 3 -DOF platform was $37^{\circ}$, which was also better than the corn harvesters with lateral tilting angles of $33^{\circ}, 18^{\circ}$ and $29^{\circ[17-19]}$, respectively.

Table 6 Results of the virtual orthogonal test

\begin{tabular}{|c|c|c|c|c|c|c|c|c|c|c|c|c|c|c|c|c|c|c|c|c|c|c|c|}
\hline NO. & $A$ & $B$ & $C$ & $D$ & $\alpha_{0} /\left(^{\circ}\right)$ & NO. & $A$ & $B$ & $C$ & $D$ & $\alpha_{0} /\left(^{\circ}\right)$ & NO. & $A$ & $B$ & $C$ & $D$ & $\alpha_{0} /\left(^{\circ}\right)$ & NO. & $A$ & $B$ & $C$ & $D$ & $\alpha_{0} /\left(^{\circ}\right)$ \\
\hline 1 & 1 & 6 & 7 & 2 & 33 & 17 & 2 & 5 & 8 & 1 & 40 & 33 & 4 & 5 & 3 & 2 & 43 & 49 & 4 & 8 & 1 & 6 & 36 \\
\hline 2 & 3 & 6 & 4 & 1 & 33 & 18 & 8 & 4 & 5 & 2 & 34 & 34 & 3 & 8 & 5 & 4 & 28 & 50 & 2 & 3 & 4 & 6 & 41 \\
\hline 3 & 4 & 6 & 8 & 7 & 35 & 19 & 2 & 4 & 7 & 3 & 41 & 35 & 2 & 6 & 3 & 8 & 32 & 51 & 3 & 7 & 2 & 5 & 26 \\
\hline 4 & 2 & 8 & 6 & 5 & 34 & 20 & 6 & 2 & 7 & 4 & 38 & 36 & 1 & 5 & 4 & 7 & 34 & 52 & 5 & 5 & 5 & 5 & 31 \\
\hline 5 & 7 & 7 & 7 & 7 & 31 & 21 & 1 & 1 & 1 & 1 & 29 & 37 & 3 & 3 & 3 & 3 & 38 & 53 & 1 & 8 & 2 & 3 & 27 \\
\hline 6 & 5 & 1 & 8 & 3 & 37 & 22 & 1 & 3 & 8 & 4 & 28 & 38 & 2 & 7 & 1 & 4 & 34 & 54 & 6 & 6 & 6 & 6 & 39 \\
\hline 7 & 4 & 3 & 7 & 5 & 39 & 23 & 4 & 1 & 2 & 8 & 39 & 39 & 6 & 5 & 1 & 3 & 40 & 55 & 2 & 2 & 2 & 2 & 41 \\
\hline 8 & 1 & 2 & 6 & 8 & 21 & 24 & 8 & 2 & 4 & 3 & 33 & 40 & 3 & 2 & 1 & 7 & 36 & 56 & 4 & 7 & 6 & 3 & 37 \\
\hline 9 & 7 & 4 & 1 & 8 & 20 & 25 & 5 & 2 & 3 & 6 & 42 & 41 & 5 & 7 & 4 & 8 & 38 & 57 & 8 & 7 & 3 & 1 & 42 \\
\hline 10 & 5 & 3 & 1 & 2 & 35 & 26 & 7 & 6 & 5 & 3 & 32 & 42 & 1 & 4 & 3 & 5 & 32 & 58 & 8 & 6 & 1 & 5 & 27 \\
\hline 11 & 7 & 2 & 8 & 5 & 25 & 27 & 5 & 4 & 6 & 7 & 31 & 43 & 3 & 1 & 6 & 2 & 29 & 59 & 7 & 3 & 6 & 1 & 27 \\
\hline 12 & 8 & 8 & 8 & 8 & 35 & 28 & 8 & 1 & 7 & 6 & 34 & 44 & 6 & 1 & 4 & 5 & 40 & 60 & 5 & 8 & 7 & 1 & 38 \\
\hline 14 & 6 & 4 & 2 & 1 & 37 & 30 & 3 & 4 & 8 & 6 & 31 & 46 & 4 & 2 & 5 & 1 & 41 & 62 & 6 & 3 & 5 & 8 & 36 \\
\hline 15 & 5 & 6 & 2 & 4 & 33 & 31 & 6 & 7 & 8 & 2 & 38 & 47 & 4 & 4 & 4 & 4 & 42 & 63 & 8 & 3 & 2 & 7 & 29 \\
\hline 16 & 2 & 1 & 5 & 7 & 33 & 32 & 7 & 5 & 2 & 6 & 30 & 48 & 1 & 7 & 5 & 6 & 28 & 64 & 8 & 5 & 6 & 4 & 36 \\
\hline
\end{tabular}


The results of range analysis and ANOVA are shown in Tables 7 and 8 . According to the results of the virtual orthogonal test, the summation value $K_{j}(j=1,2,3, \ldots, 8)$, the average value $k_{j}(j=1,2$, $3, \ldots, 8)$ and the range value $R$ of the evaluation index $\alpha_{0}$ could be calculated. Table 7 shows that the value $R$ of $A, B, C$ and $D$ were
10.6, 3.3, 5.3 and 4.1 respectively, and the order of the influence intensity of factors on tilting stability was $A>C>D>B$, i.e., $\beta_{1}>h$ $>m>\beta_{2}$. Table 8 shows that $A$ and $C$ had highly significant effect on $\alpha_{0}, D$ had a significant effect on $\alpha_{0}$, while $B$ had no significant effect on $\alpha_{0}$.

Table 7 Results of range analysis

\begin{tabular}{|c|c|c|c|c|c|c|c|c|c|c|c|c|c|c|c|c|c|}
\hline \multirow{2}{*}{ Factors } & \multicolumn{8}{|c|}{ Summation value } & \multicolumn{8}{|c|}{ Average value } & \multirow{2}{*}{$\frac{\text { Range }}{R}$} \\
\hline & $K_{1}$ & $K_{2}$ & $K_{3}$ & $K_{4}$ & $K_{5}$ & $K_{6}$ & $K_{7}$ & $K_{8}$ & $k_{1}$ & $k_{2}$ & $k_{3}$ & $k_{4}$ & $k_{5}$ & $k_{6}$ & $k_{7}$ & $k_{8}$ & \\
\hline$A$ & 248.0 & 296.0 & 257.0 & 312.0 & 285.0 & 307.0 & 227.0 & 270.0 & 31.0 & 37.0 & 32.1 & 39.0 & 35.6 & 38.4 & 28.4 & 33.8 & 10.6 \\
\hline$C$ & 257.0 & 262.0 & 297.0 & 294.0 & 263.0 & 254.0 & 290.0 & 269.0 & 32.1 & 32.8 & 37.1 & 36.8 & 32.9 & 31.8 & 36.3 & 33.6 & 5.3 \\
\hline$D$ & 287.0 & 286.0 & 285.0 & 273.0 & 264.0 & 281.0 & 268.0 & 257.0 & 35.9 & 35.8 & 35.6 & 34.1 & 31.8 & 35.1 & 33.5 & 32.1 & 4.1 \\
\hline
\end{tabular}

Table 8 Results of ANOVA

\begin{tabular}{|c|c|c|c|c|c|c|c|}
\hline Evaluation index & Source of variation & Sum of squares & Freedom & Mean squares & $F$-value & $p$-value & Significance \\
\hline \multirow{4}{*}{$\alpha_{0}$} & Correction model & 1405.000 & 28 & 50.179 & 5.236 & 0.001 & $* *$ \\
\hline & $A$ & 926.438 & 7 & 132.348 & 13.809 & 0.001 & $* *$ \\
\hline & $C$ & 269.938 & 7 & 38.563 & 4.024 & 0.003 & $* *$ \\
\hline & $D$ & 154.938 & 7 & 22.134 & 2.309 & 0.048 & $*$ \\
\hline
\end{tabular}

Note: *indicates significance $(p<0.05)$; $* *$ indicates highly significance $(p<.01)$.

Combined with the critical tilting angles obtained from the above study, the influence of factors on tilting stability could be concluded as follows.

(1) The changes of $\alpha_{0}$ with $\beta_{1}$ and $\beta_{2}$ when $h$ and $m$ were fixed values.

Setting $m$ to $150 \mathrm{~kg}$ and $h$ to $1.2 \mathrm{~m}$, when $\beta_{1}$ assumed different values, $\alpha_{0}$ changed with increasing $\beta_{2}$, and there was always a operating position with a minimum critical tilting angle $\alpha_{0 \min }$. As shown in Table 9, $\beta_{1}, \beta_{2}$, and $\alpha_{0 \min }$ could be expressed as $\left(\beta_{1}, \beta_{2}\right.$, $\left.\alpha_{0 \text { min }}\right)$, then there were $(0,0,20),(45,315,23),(90,270,23),(135$, $225,29),(180,180,23),(225,135,22),(270,90,21)$, and $(315,45$, 24). Obviously, $\beta_{2}$ was equal to $-\beta_{1}+360^{\circ}$, and it indicated that the operating position of the manned worktable along the slope down was always most prone to tilt. This was consistent with the results of the tilting stability theoretical analysis.

Table 9 Tilting angles of different parked and rotary positions

\begin{tabular}{ccccccccc}
\hline \multirow{2}{*}{$\begin{array}{c}\text { Parked } \\
\text { position/ }\left({ }^{\circ}\right)\end{array}$} & \multicolumn{7}{c}{ Critical tilting angle at different rotary positions $/\left({ }^{\circ}\right)$} \\
\hline 0 & 0 & 45 & 90 & 135 & 180 & 225 & 270 & 315 \\
\hline 45 & 20 & 22 & 25 & 28 & 29 & 28 & 26 & 23 \\
90 & 26 & 25 & 28 & 30 & 30 & 27 & 25 & 23 \\
135 & 34 & 39 & 38 & 37 & 34 & 29 & 30 & 31 \\
180 & 33 & 31 & 30 & 29 & 28 & 30 & 31 & 33 \\
225 & 31 & 28 & 25 & 22 & 24 & 26 & 29 & 31 \\
270 & 26 & 23 & 21 & 23 & 25 & 28 & 29 & 28 \\
315 & 25 & 24 & 25 & 27 & 30 & 32 & 30 & 27 \\
\hline
\end{tabular}

(2) The changes of $\alpha_{0}$ with $h$ when $\beta_{1}, \beta_{2}$, and $m$ were fixed values.

Setting $m$ to $150 \mathrm{~kg}$ and $\beta_{1}$ to $0^{\circ}$, when $\beta_{2}$ assumed different values, the changes of $\alpha_{0}$ with $h$ are shown in Figure 9. Due to the limitation of installation space of the lifting platform, the manned table could not rotate $360^{\circ}$ at any lifting height. Therefore, the height from $0.6 \mathrm{~m}$ to $1.2 \mathrm{~m}$ was selected without affecting the results of the analysis. When $\beta_{2}$ was $0^{\circ}, 45^{\circ}$, and $315^{\circ}$, with increasing $h, \alpha_{0}$ first decreased and then increased. When $\beta_{2}$ was $90^{\circ}, 135^{\circ}, 180^{\circ}, 225^{\circ}$, and $270^{\circ}$, with increasing $h, \alpha_{0}$ gradually decreased. This meant that when the manned table was along the downward slope, the tilting stability first decreased and then increased with increasing lifting height, and when the manned table was along the upward slope, the tilting stability decreased with increasing lifting height. Furthermore, regardless of which position the platform parked on the slope, the influence of the lifting height on the tilting stability corresponded with the above rules.

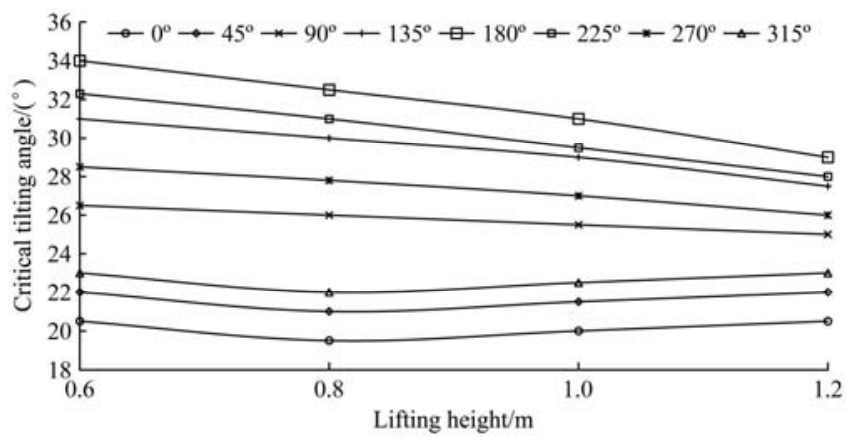

Figure 9 Critical tilting angles as lifting height increased

(3) The changes of $\alpha_{0}$ with $m$ when $\beta_{1}, \beta_{2}$, and $h$ were fixed values.

Setting $h$ to $1.2 \mathrm{~m}$ and $\beta_{1}$ to $0^{\circ}$, when $\beta_{2}$ assumed different values, the changes of $\alpha_{0}$ with $m$ are shown in Figure 10. With increasing $m, \alpha_{0}$ gradually decreased. This indicated that when the manned worktable rotated to any position, the tilting stability decreased with increasing load. Furthermore, regardless of which position the platform parked on the slope, the influence of the load on the tilting stability corresponded with the above rules.

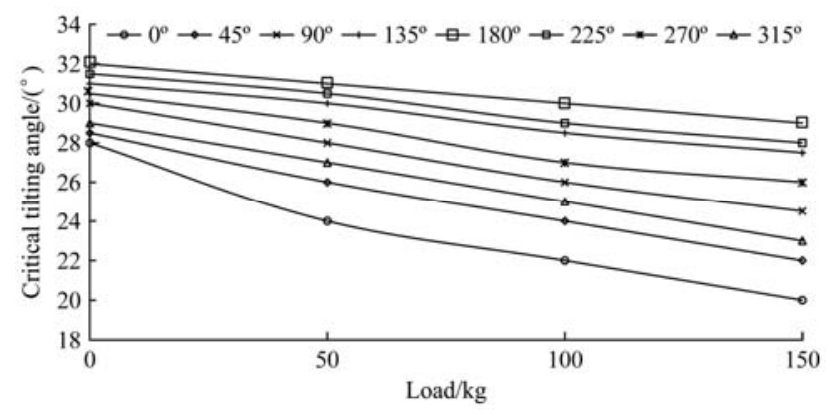

Figure 10 Critical tilting angles as the load increased 


\section{Conclusions}

A tilting stability analysis was carried out based on the structure and operating characteristics of the 3-DOF lifting platform for hilly orchards. Due to the ability of the platform to park at any position on the slope, analysis was conducted in three parts: tilting stability in the longitudinal direction, the transverse direction, and the oblique direction, respectively, which could be evaluated via the critical tilting angle. According to the theoretical expressions of the critical tilting angle, the following influencing factors of the tilting stability were obtained: parked position $\beta_{1}$, manned worktable rotary position $\beta_{2}$, lifting height $h$, and load $m$.

The critical tilting angles of simulation results $\left(\alpha_{0}\right)$ had a relative error of approximately $4.6 \%$ compared to the results of the tilting experiment verification, which indicated that the simulation had a high accuracy, and could be used to analyze the influencing factors on tilting stability. Moreover, the dynamic tilting simulation of climbing and lateral driving was carried out, and the results were $1^{\circ}-2^{\circ}$ smaller than the static tilting angles. This difference could be also used to predict the dynamic tilting angles based on the static tilting angles.

A virtual orthogonal test was conducted for the influencing factors $\beta_{1}, \beta_{2}, h$, and $m$. The critical tilting angle ranged from $20^{\circ}$ to $44^{\circ}$ when the factors were at different values, which indicated that the 3-DOF lifting platform for hilly orchards had a high tilting stability performance and could adapt to the operating conditions of hills with slope angles from $5^{\circ}$ to $20^{\circ}$. Then, the results of the range analysis and ANOVA showed that the influence intensity of factors on tilting stability was $\beta_{1}>h>m>\beta_{2}$; at the same time, $\beta_{1}$, $h$, and $m$ had significant effect on tilting stability. In addition, when the manned worktable was along the downward slope, the platform had the lowest tilting stability. With increasing lifting height, the tilting stability first decreased and then either increased or decreased with different rotary positions of the manned worktable, while, with increasing load, the tilting stability gradually decreased.

This research can provide guidance for safety operation and a theoretical basis for evaluating the tilting stability of the 3-DOF lifting platform; additionally, the analysis method mentioned in the article can also be applied to the tilting stability analysis of other types of lifting machinery for hilly orchards.

\section{Acknowledgements}

The research was financially supported by Co-Innovation Center of the Intelligent Management and Equipment for Orchard on the Hilly Land in south China (JX2014XCHJ02).

\section{[References]}

[1] Fan G J, Wang Y Z, Zhang X H, Zhao J Y, Song Y P. Design and experiment of automatic leveling control system for orchards lifting platform. Transactions of the CSAE, 2017; 33(11): 38-46. (in Chinese)

[2] Charles M F, Adrian K L. Rollover risk of cars and light trucks after accounting for driver and environmental factors. Accident Analysis and Prevention, 2002(34): 163-173.

[3] Eger R, Kiencke U. Modeling of rollover sequences. Control Engineering Practice, 2003; 11(2): 209-216.

[4] Xiao J, Lei Y C, Zhang P, Tang T J, Bai B. Analysis of the maximum static stable roll angle of the vehicle and the sensitivity of the main influence factor. Manufacture Information Engineering of China, 2006; 35(11): 64-67. (in Chinese)

[5] Jin Z L, Weng J S, Hu H Y. Rollover stability of a vehicle during critical driving manoeuvres. Proceedings of the Institution of Mechanical
Engineers, 2007; 221(9): 1041-1049.

[6] Maclenman P A, Marshall T, Griffin R. Vehicle rollover risk and electronic stability control systems. Injury prevention, 2008; 14(3): $154-158$.

[7] Wu X Y, Ge X H, Luo S Y, Hang H W. Study on stability of rollover of vehicle. Journal of Xiamen University: Natural Science, 2010; 49(6): 815-818. (in Chinese)

[8] Gaspar P, Szaszi I, Bokor J. The design of a combined control structure to prevent the rollover of heavy vehicles. European Journal of Control, 2004; 10(2): 148-162.

[9] Péter G, István S, József B. Two Strategies for reducing the rollover risk of heavy vehicles. Erbarzt, 2005; 33(1): 139-147.

[10] Gaspar P, Szaszi I, Bokor J. Reconfigurable control structure to prevent the rollover of heavy vehicles. Control Engineering Practice, 2005; 13(6): 699-711.

[11] Tankut A. Rollover prevention for heavy trucks using frequency shaped sliding mode control. Vehicle System Dynamics, 2006; 44(10): 737-762.

[12] Zhao D X, Cheng Y S, Zhu W N, Zhang Z D. The dynamical solution on stability of articulated tractor overturning. Transactions of the CSAM, 1995; 26(3): 1-4. (in Chinese)

[13] Gravalos I, Gialamas T, Loutridis S, Moshou D, Kateris D, Xyradakis P, et al. An experimental study on the impact of the rear track width on the stability of agricultural tractors using a test bench. Journal of Terramechanics, 2011; 48(4): 319-323.

[14] Serap G, Eugenio C. Perceptions of tilt angles of an agricultural tractor. Journal of Agromedicine, 2014; 19(1): 5-14.

[15] Zhu Y Q, Hong T S, Wu W B, Song S R, Li Z, Mo W B. Design and simulation of side rollover resistant capability of tracked vehicle for mountain orchards. Transactions of the CSAM, 2012; 43(Supp.1): 19-23. (in Chinese)

[16] Bruno F, Roland L, Valda R. Comparison between a rollover tractor dynamic model and actual lateral tests. Biosystems Engineering, 2014; 127:79-91.

[17] Liu N, Sun H W, Chen X Z, Liu R, Zhou X. Research on the rollover stability of 4YZP-2 corn harvester. Journal of Chinese Agricultural Mechanization, 2014; 35(6): 38-41. (in Chinese)

[18] Du Y F. Design Method and Experimental research on self-propelled corn harvester for hilly and mountainous region. Beijing: China Agricultural University, 2014, 5. (in Chinese)

[19] Ma L N, Du Y F, Song Z H, Mao E R. Mathematical Modeling and Experiment of Corn Harvester Quasi-static Lateral Stability. Transactions of the CSAM, 2016; 47(7): 89-95. (in Chinese)

[20] [20] Maurizio C, Massimo B, Carlo B, Stefano M. A study of the lateral stability of self-propelled fruit harvesters. Agriculture, 2017; 7(11): 1-13.

[21] Liu X N, Zhu H T, Ba H T. Development of a Faun LG1 type multifunctional orchard operating machine. Xinjiang Agricultural Mechanization, 2009; 2(1): 42-44. (in Chinese)

[22] Masao N. Development and improvement of mobile work platform for use in apple orchards. Japanese Journal of Farm Work Research, 2006; 41(2): 68-73.

[23] Liu D W, Xie F P, Li X, Wang X L. Design and experiment of small lifting platform in orchard. Transactions of the CSAE, 2015; 31(3): 113-121. (in Chinese)

[24] Gokhan B, Marcel B, Koku A B, Konukseven E. Localization and control of an autonomous orchard vehicle. Computers and Electronics in Agriculture, 2015(115): 118-128.

[25] Du Y F, Mao E R, Song Z H, Zhu Z X, Gao J M. Simulation on corn plants in harvester process based on ADAMS. Transactions of the CSAM, 2012; 43(supp.1): 106-111. (in Chinese)

[26] Bauer G, Springholz G. Dynamic simulation and analysis of a new type of hydraulic fork lifting platform based on Recurdyn. Machine Tool \& Hydraulics, 2015, 1: 96-100.

[27] Liu N. Research on the rollover stability of 4YZP-2 corn harvester. Taiyuan: Taiyuan University of Technology, 2014.6. (in Chinese)

[28] Zhang J W, Peng B B. Multi-body system optimization simulation technology for recurdyn. Beijing: Tsinghua University Press, 2010; pp: 176-180. (in Chinese)

[29] Lu J Q, Yang Y, Li Z H, Shang Q Q, Li J C, Liu Z Y. Design and experiment of an air-suction potato seed metering device. Int $\mathrm{J}$ Agric \& Biol Eng, 2016; 9(5): 33-42.

[30] Zhao X M. Test design method. Beijing: Science Press, 2006; pp: 66-78. (in Chinese) 